\title{
Risk factors for sickness absence due to low back pain and prognostic factors for return to work in a cohort of shipyard workers
}

\author{
Evangelos C. Alexopoulos · Eleni C. Konstantinou • \\ Giorgos Bakoyannis · Dimitra Tanagra • \\ Alex Burdorf
}

Received: 19 November 2007 /Revised: 25 April 2008/ Accepted: 18 June 2008/Published online: 23 July 2008

(C) The Author(s) 2008

\begin{abstract}
The purpose of this study was to determine risk factors for the occurrence of sickness absence due to low back pain (LBP) and to evaluate prognostic factors for return to work. A longitudinal study with 1-year follow-up was conducted among 853 shipyard workers. The cohort was drawn around January 2004 among employees in the shipyard industry. Baseline information was obtained by questionnaire on physical and psychosocial work load, need for recovery, perceived general health, musculoskeletal complaints, sickness absence, and health care use during the past year. During the 1-year follow-up for each subject medical certifications were retrieved for information on the frequency and duration of spells of sickness absence and associated diagnoses. Cox regression analyses were conducted on occurrence and on duration of sickness absence with hazard ratios (HR) with 95\% confidence interval $(95 \% \mathrm{CI})$ as measure of association. During the 1year follow-up period, $14 \%$ of the population was on sick leave at least once with LBP while recurrence reached $41 \%$. The main risk factors for sickness absence were
\end{abstract}

E. C. Alexopoulos $(\square)$

Department of Public Health, Medical School,

University of Patras, Rio, 26500 Patras, Greece

e-mail: ecalexop@upatras.gr

E. C. Alexopoulos - E. C. Konstantinou - D. Tanagra

Occupational Health Department,

Hellenic Shipyards SA, Athens, Greece

G. Bakoyannis

Department of Hygiene and Epidemiology,

Medical School, Athens University, Athens, Greece

A. Burdorf

Department of Public Health, Erasmus MC,

Rotterdam, The Netherlands previous absence due to a health problem other than LBP (HR 3.07; 95\%CI 1.66-5.68) or previous sickness absence due to LBP (HR 6.52; 95\%CI 3.16-13.46). Care seeking for LBP and lower educational level also hold significant influences (HR 2.41; 95\%CI 1.45-4.01 and HR 2.46; 95\% CI 1.19-5.07, respectively). Living with others, night shift and supervising duties were associated with less absenteeism due to LBP. Workers with a history of herniated disc had a significantly decreased rate of returning to work, whereas those who suffered from hand-wrist complaints and LBP returned to work faster. Prior sick leave due to LBP partly captured the effects of work-related physical and psychosocial factors on occurrence of sick leave. Our study showed that individual and job characteristics (living alone, night shift, lower education, sick leave, or care seeking during the last 12 months) influenced the decision to take sick leave due to LBP. An increased awareness of those frequently on sick leave and additional management after return to work may have a beneficial effect on the sickness absence pattern.

Keywords Low back pain - Sick leave - Prognosis . Recurrence $\cdot$ Return to work

\section{Introduction}

A high prevalence of work-related low back pain (LBP) with substantial consequences has been reported among industrial workers. [14] In the shipyard industry metal workers, welders, carpenters, plumbers, mechanics, and various other workers hold jobs that include most of the well-established risk factors for the occurrence of LBP and other musculoskeletal disorders (MSDs) such as physical load and psychosocial stressors $[2,8,19]$. 
Sickness absence is an important indicator of morbidity, although it is not a simple function of ill health since it also includes psychological factors and coping behaviors. Coping strategies may depend on individual, social, organizational, and cultural factors, which negatively affect the prognosis of temporary disability and recovery. This underlines the need of ongoing research on factors affecting the worker's ability to cope with his/her musculoskeletal problem at work in different settings and cultures. More knowledge about the risk factors of sickness absence will be valuable in determining strategies for reducing sick leave and this underlines why its monitoring is an essential part of occupational health care $[1,5,10]$. While there is evidence for the effectiveness of return to work (RTW) interventions [18], the results are not consistent across studies either on reducing recurrent absenteeism due to $\operatorname{LBP}[16,17,25]$ or on improving RTW [4]. Furthermore, the challenges of engaging and involving stakeholders in RTW intervention and the necessity of expanding RTW research to more diverse work settings are well acknowledged [11].

In most cases RTW after sick leave due to LBP occurs within 1 month [12, 28]. Although it is of great importance to distinguish workers with normal RTW from those with prolonged sick leave, this has shown to be difficult. Individual and complaint-related characteristics, social parameters, and pursuit of compensation have been identified as predictors for a delayed return to work among patients with LBP [30].

The aim of this longitudinal study was to describe the frequency and duration of sickness absence due to LBP, to investigate risk factors for the occurrence of sickness absence, and to determine the prognostic factors for RTW.

\section{Methods}

\section{Study population}

The study population consisted of employees of a company involved in shipbuilding and ship repairing in Greece. In 2004, the total workforce reached 1,400 employees. Most employees will undergo a medical examination every 2 year, consisting of a general part and a specific part tailored to the relevant occupational exposures in the job involved.

Baseline data were collected through questionnaires in the period between December 2003 and February 2004. Throughout this period during the routinely health examination in the occupational health department, all employees were asked to participate in the study by giving their informed consent. The response was $98.5 \%$ (919/933 employees). The inclusion was 93\% (853/919 employees). The principal reason for non-inclusion was the lack of fulfillment of the only criterion for eligibility to the study that was at least 1 year of work experience in the current position.

Study design and data collection

The self-administered questionnaire at baseline involved information on the respondent's job history, individual characteristics, physical and psychosocial risk factors at work, general health status, and the occurrence of musculoskeletal complaints. Individual characteristics and work history included questions on age, anthropometry, gender, family situation, level of education, duration of employment, previous jobs held, and smoking status. Questions on physical work load concerned manual materials handling, awkward working postures, and strenuous arm positions on a four-point scale with 'often' and 'always' classified as high exposure [2]. Perceived exertion was rated from 6 (very light) till 20 (very heavy) with a score above the median value (16) considered as high perceived exertion. [6]. Psychosocial aspects focused on demands (10 items) and job control (14 items) [21]. All items were scored on a four-point scale, sum scores were calculated with scores above the median value indicating the presence of a psychosocial risk.

The health status of each subject was ascertained by three different outcomes, i.e., perceived general health (10 dichotomous questions on health complaints in past 12 months), need for recovery (11 dichotomous questions on past workday), and musculoskeletal complaints. For perceived general health (10 dichotomous questions on health complaints in past 12 months) and need for recovery, subjects with a sum score above the median value were considered to have a moderate health or a high need for recovery. Musculoskeletal complaints ascertained the presence in the past 12 months and associated sickness absence and type of care seeking, including a GP, a specialist, a physiotherapist or the occupational physician (OP).[23].

During the 1-year follow-up, for each subject information on the frequency and duration of spells of sickness absence was retrieved from medical certifications issued by physicians of the Social Insurance Institute. The worker on sick leave will be compensated by the company with $50 \%$ of his wage, except for occupational accidents. In order to verify the cause of absence, on return to work medical staff interviewed the worker and categorized sickness absence into 13 diseases groups, whereby MSDs were further categorized into low back disorders, neck or shoulder disorder, knee, upper and lower extremity disorders. A return to work in full duty of at least 1 day was needed to consider the next episode of sick leave as a new event. 
Statistical analysis

Univariate analyses were performed to examine the effects of socio-demographic, occupational and health-related characteristics on the time to the first spell of sickness absence due to LBP. The Cox proportional hazards model was used to study risk factors simultaneously and to adjust for potential confounders. In order to model the corresponding hazard function, all relevant variables (criterion of $P<0.15)$ from the univariate analyses were included in a backwards elimination procedure (removal criterion 0.10 level of significance). In the resulting model, non-significant variables from univariate analyses were added, one at time, in order to identify the final significant variables (inclusion criterion 0.10 level of significance) [22]. For this procedure, likelihood ratio tests were applied. In the final regression model, variables at 0.05 level of significance were retained (Wald test) and age was included in all steps of the analysis regardless of its level of significance. The hazard ratio and $95 \%$ CI were calculated for each factor. The hazard ratio is interpreted as the ratio of instantaneous event rates at any time during the follow-up. All statistical analyses were performed with STATA software. The general fit of the final model was done by inspection of the plot of Cox-Snell residuals. The check on the proportional hazards assumption was undertaken by the test of Schoenfeld residuals.

In addition, we analyzed the time to return to work, modeling its hazard function after the start of the first absence due to LBP. In this analysis exact partial likelihood was used for estimation because of multiple ties in return times. None of the employees with an absence due to LBP were censored in the analysis since they all returned to work before the termination of the follow-up.

\section{Results}

\section{Response}

The final cohort consisted of 853 employees. Of 853 employees, 287 were metal workers $(33.6 \%), 93$ were welders $(10.9 \%)$ and 229 (26.8\%) were white-collar workers. Other blue collar jobs consisted of drivers/crane operators, carpenters, electricians, sandblasters/painters, and a variety of miscellaneous jobs. During the 1-year follow-up $8(0.94 \%)$ workers were lost to follow-up due to a change of job.

\section{Baseline characteristics}

The basic characteristics of the 853 workers with complete data are shown in Table 1. Only among white collars there were $56(24.5 \%)$ female employees. The subjects consisted predominantly of blue collars who had graduated with 2 or 3 year secondary school of technical expertise $(n=603)$. At baseline, $37 \%(n=314)$ of the study population had experienced an episode of LBP, $18.9 \%(n=161)$ sought care, $15 \%(n=131)$ took sick leave in the 12 months preceding the investigation, and 35\% reported at least two musculoskeletal complaints (Table 1). In the past 12 months 507 (59.4\%) employees took a sick leave due to any cause at least once. The lifetime prevalence of LBP was $55.8 \%(n=476)$, of shoulder/neck pain $29.7 \%$ $(n=253)$ and of hand/wrist pain $21 \%(n=179)$. Among those workers with LBP in the past 12 months, approximately $52 \%$ had sought health care and $42 \%$ had been on sick leave at least once. Among workers with shoulder/ neck pain or hand/wrist pain the proportion seeking health care was comparable to those with LBP, but the proportion with sick leave was lower.

\section{Sickness absence during the follow-up period}

In total, 483 of 853 employees (56\%) took a sick leave due to any cause during the 1-year follow-up, and in total 1,049 sickness absence periods were registered, ranging between 1 and 12 periods per person. Low back pain was the most frequent single cause of absence with 119 (14\%) employees who experienced at least one episode of sickness absence due to LBP. The overall rate $(95 \% \mathrm{CI})$ of absence due to LBP was $15.6(13.1-18.7)$ per 100 person-years, ranging between 9.5 (7.4-12.2) and 56.4 (43.4-73.3) for those without and with sick leave during last year, respectively.

Welders exhibited a higher incidence of sick leave due to LBP $(18.3 \%)$, while the other groups ranged between 12.9 and $14.3 \%$. Those workers who reported LBP $(n=312)$ and previous absence due to any cause at baseline $(n=507)$ took more sick leave $(23.7 \%)$ and (20.7\%) compared to others $(8.4 \%)$ and $(4.3 \%)$, respectively. The probability of a recurrent sickness absence within 1 year was significantly higher than the probability of a first sickness absence within 1 year. For LBP a 1 year recurrence risk of $43.1 \%$ was found. The Kaplan-Meier curve of sick leave due to LBP, stratified by previous absence, is shown in Fig. 1. Fewer supervisors (i.e. employees with at least 2 employees under surveillance) took a sick leave due to LBP $(n=305,10.2 \%)$, compared to those with no supervising duties $(n=548,16.1 \%)$. Of those with no previous LBP $8.4 \%$ took a sick leave due to LBP while recurrence was $23.7 \%$.

Table 2 presents the factors that were statistically significantly associated with the occurrence of sickness absence due to LBP. The main risk factors for sickness absence were previous absence due to health problem other 
Table 1 Individual characteristics, self-reported risk factors, and health status of shipyard employees at baseline $(n=853)$

\begin{tabular}{|c|c|c|c|c|c|}
\hline & $\begin{array}{l}\text { White-collar workers } \\
(n=229)\end{array}$ & $\begin{array}{l}\text { Metal workers } \\
(n=287)\end{array}$ & $\begin{array}{l}\text { Welders } \\
(n=93)\end{array}$ & $\begin{array}{l}\text { Other blue collars } \\
(n=244)\end{array}$ & $\begin{array}{l}\text { All employees } \\
(n=853)\end{array}$ \\
\hline Age $[y$, mean $(\mathrm{SD})]$ & $36.8(9.1)$ & $37.8(9.8)$ & $38.4(9.7)$ & $39.7(8.8)$ & $38.2(9.5)$ \\
\hline Duration of employment [y, mean (SD)] & $9.5(8.8)$ & $15.4(10.2)$ & $17.3(10.7)$ & $15.9(9.4)$ & $14.3(10.1)$ \\
\hline Body mass index $\left(\mathrm{kg} / \mathrm{m}^{2}\right.$, mean $\left.(\mathrm{SD})\right)$ & $26.1(4.8)$ & $27.2(4.1)$ & $27.1(3.9)$ & $27.9(4)$ & $27(4.3)$ \\
\hline Technical/Basic educational level (\%) & 53.1 & 96.1 & 100 & 95.7 & 85.0 \\
\hline Living with relatives/friends (\%) & 75.5 & 89.2 & 85 & 86.2 & 84.3 \\
\hline \multicolumn{6}{|l|}{ Smoking $(\%)$} \\
\hline Never & 33.2 & 23.4 & 19.4 & 22.4 & 25.2 \\
\hline Ex-smokers & 15.3 & 14.7 & 14 & 16.4 & 15.5 \\
\hline Current & 51.6 & 61.9 & 66.7 & 61.2 & 59.3 \\
\hline Manual material handling ${ }^{\mathrm{a}}(\%)$ & 6.2 & 24.2 & 12.5 & 22.6 & 17.6 \\
\hline Strenuous shoulder/hand movements ${ }^{\mathrm{a}}(\%)$ & 34.6 & 67 & 73.5 & 63.6 & 58.0 \\
\hline Strenuous (awkward) postures ${ }^{\mathrm{a}}(\%)$ & 17.3 & 54.9 & 54.6 & 51.6 & 43.7 \\
\hline Perceived exertion [score, mean (SD)] & $11.1(3.7)$ & $14(2.5)$ & $14.1(2.9)$ & $13.9(3)$ & $13.2(3.3)$ \\
\hline Decision authority [score, mean (SD)] & $35.5(26.7)$ & $43.8(29.3)$ & $52.5(33.9)$ & $46.5(29.2)$ & $43.3(29.4)$ \\
\hline Skill discretion [score, mean (SD)] & $46.3(32.6)$ & $33(27.2)$ & $36.5(28.3)$ & $36.9(27.6)$ & $38.1(29.4)$ \\
\hline Job demands [score, mean (SD)] & $44.8(22.3)$ & $37.3(21.5)$ & $35.1(23)$ & $36.3(20.4)$ & $38.6(21.9)$ \\
\hline Need for recovery [score, mean (SD)] & $40.6(28.5)$ & $40(25.9)$ & $40.4(29)$ & $38.8(27.2)$ & $39.6(27.3)$ \\
\hline Perceived general health (score, mean (SD) & $21.7(21.4)$ & $15.6(18.1)$ & $20.7(21.1)$ & $18.7(19.1)$ & $18.5(19.7)$ \\
\hline \multicolumn{6}{|l|}{ Low back pain in past 12 months (\%) } \\
\hline Prevalence & 39.3 & 33 & 39.8 & 37.9 & 36.8 \\
\hline Sick leave & 14.8 & 12.2 & 17.2 & 18.9 & 15.4 \\
\hline Health care use & 17.9 & 17 & 20.4 & 21.4 & 18.9 \\
\hline \multicolumn{6}{|l|}{ Shoulder/neck pain in past 12 months (\%) } \\
\hline Prevalence & 27.9 & 14.6 & 18.3 & 25.2 & 21.6 \\
\hline Sick leave & 4.4 & 4.4 & 7.5 & 5 & 4.9 \\
\hline Health care use & 11.8 & 7.5 & 8.6 & 8 & 8.9 \\
\hline \multicolumn{6}{|l|}{ Hand/wrist pain in past 12 months (\%) } \\
\hline Prevalence & 17 & 15.3 & 10.8 & 13.4 & 14.8 \\
\hline Sick leave & 2.6 & 4.1 & 2.2 & 2.9 & 3.2 \\
\hline Health care use & 6.6 & 7.1 & 5.4 & 8.4 & 7.2 \\
\hline \multicolumn{6}{|l|}{ Comorbidity } \\
\hline Low back and shoulder/neck pain & 16.7 & 8.5 & 10.8 & 14.8 & 12.7 \\
\hline Low back and hand/wrist pain & 10.5 & 8.5 & 7.5 & 8 & 8.8 \\
\hline
\end{tabular}

${ }^{\text {a }}$ Proportion of workers classified as high exposure

than LBP (HR 3.07; 95\%CI 1.66-5.68) or previous sickness absence due to LBP (HR 6.52; 95\%CI 3.16-13.46). Care seeking for LBP and a lower educational level hold significant influences (HR 2.41; 95\%CI 1.45-4.01 and HR 2.46; 95\%CI 1.19-5.07, respectively). Living with others and work at night shift duties were associated with less absenteeism due to LBP. Supervising duties hold a marginal influence on less future sick leave (HR 0.68; 95\% CI 0.44-1.03). Absence due to low back complaints was not associated with age, height, body mass index and, smoking. Work-related physical and psychosocial factors did not exhibit a significant influence on absenteeism due to LBP in the whole study population. When only those without prior absence due to LBP were included in the analysis, manual materials handling (HR 1.91; 95\%CI 1.06-3.44) and a high need for recovery (HR 1.67; 95\%CI 0.99-2.83) were significantly associated in the univariate analyses, but did not reach a statistical significance in the final multivariate model.

Most workers (92\%) returned to work within 2 weeks. All but one worker returned to their regular duties after RTW. Only in 3 cases $(2.5 \%)$ the duration of sickness absence exceeded 1 month and all occurred in workers with more than one absence. Table 3 shows the significant prognostic factors for return to work during the first period of sickness absence. 

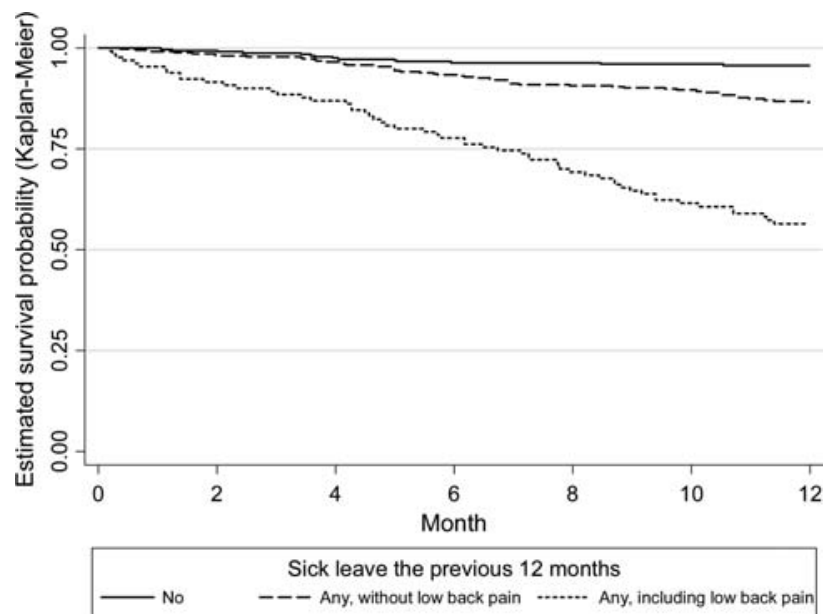

Fig. 1 Time to a first period of sickness absence due to low back pain
Workers with a history of herniated disc had a significantly decreased rate of returning to work. A history of a herniated disc besides the positive answer in the questionnaire was further confirmed by asking if an imaging technique (MRI) took place at least in 41 of 65 employees $(n=63.1 \%)$. Comorbidity showed diverse results. Those having suffered hand/wrist complaints during the past year returned to work faster after the first spell of sick leave. No other individual and job characteristics were associated with return to work.

\section{Discussion}

This longitudinal study showed that sickness absence due to LBP — with an annual incidence of $14 \%$ and a recurrence
Table 2 Hazard ratios (HRs) for sickness absence due to low back pain $(n=845)$

a Covariates of the final model

\begin{tabular}{|c|c|c|c|c|}
\hline & \multicolumn{2}{|c|}{ Unadjusted } & \multicolumn{2}{|c|}{ Adjusted for the final mode } \\
\hline & HR & $95 \% \mathrm{CI}$ & HR & $95 \% \mathrm{CI}$ \\
\hline Age (for 10 years increment) & 1.03 & $0.85-1.25$ & $1.06^{\mathrm{a}}$ & $0.87-1.29$ \\
\hline $\begin{array}{l}\text { Seen by a physician due to LBP problem } \\
\text { during the last } 12 \text { months }\end{array}$ & 5.34 & $3.73-7.66$ & $2.41^{\mathrm{a}}$ & $1.45-4.01$ \\
\hline \multicolumn{5}{|l|}{$\begin{array}{l}\text { Absence due to a health problem } \\
\text { during the last } 12 \text { months }\end{array}$} \\
\hline No & 1.00 & & 1.00 & - \\
\hline Any other than low back pain & 3.15 & $1.74-5.71$ & $3.07^{\mathrm{a}}$ & $1.66-5.68$ \\
\hline Any, including low back pain & 12.46 & $6.93-22.39$ & $6.52^{\mathrm{a}}$ & $3.16-13.46$ \\
\hline \multicolumn{5}{|l|}{ Educational level } \\
\hline Higher & 1.00 & & 1.00 & \\
\hline Technical/Basic & 2.54 & $1.24-5.20$ & $2.46^{\mathrm{a}}$ & $1.19-5.07$ \\
\hline Night shift & 0.26 & $0.06-1.05$ & $0.24^{\mathrm{a}}$ & $0.06-0.99$ \\
\hline \multicolumn{5}{|l|}{ Family situation } \\
\hline Living with relatives/friends & 1.00 & & 1.00 & \\
\hline Living alone & 1.47 & $0.95-2.29$ & $1.79^{\mathrm{a}}$ & $1.15-2.80$ \\
\hline Supervising duties & 0.63 & $0.42-0.95$ & 0.68 & $0.44-1.03$ \\
\hline High perceived exertion & 1.30 & $0.90-1.86$ & 0.85 & $0.58-1.24$ \\
\hline Manual materials handling & 1.55 & $1.00-2.40$ & 1.06 & $0.67-1.68$ \\
\hline Strenuous awkward postures & 1.45 & $0.99-2.12$ & 1.00 & $0.68-1.48$ \\
\hline High job demands & 1.31 & $0.90-1.91$ & 1.34 & $0.91-1.96$ \\
\hline High need for recovery & 1.66 & $1.13-2.45$ & 1.31 & $0.88-1.95$ \\
\hline $\begin{array}{l}\text { Moderate perceived general health } \\
\text { (non musculoskeletal comorbidity) }\end{array}$ & 1.50 & $1.04-2.18$ & 1.14 & $0.78-1.66$ \\
\hline Low back pain in past 12 months & 3.01 & $2.08-4.35$ & 0.78 & $0.40-1.53$ \\
\hline Herniated disc history & 1.84 & $1.11-3.05$ & 0.99 & $0.58-1.67$ \\
\hline \multicolumn{5}{|l|}{ Comorbidity } \\
\hline No & 1.00 & & 1.00 & \\
\hline Hand/wrist pain & 1.20 & $0.49-2.97$ & 0.58 & $0.23-1.45$ \\
\hline Shoulder/neck pain & 2.85 & $1.77-4.60$ & 1.21 & $0.72-2.04$ \\
\hline Hand/wrist and shoulder/neck pain & 1.96 & $0.99-3.91$ & 0.98 & $0.48-1.99$ \\
\hline
\end{tabular}


Table 3 Hazard ratios (HRs) for return to work after the first absence due to low back pain $(n=119)$

\begin{tabular}{|c|c|c|c|c|}
\hline & \multicolumn{2}{|c|}{ Unadjusted } & \multicolumn{2}{|c|}{$\begin{array}{l}\text { Adjusted for the } \\
\text { final model }\end{array}$} \\
\hline & HR & $95 \% \mathrm{CI}$ & HR & $95 \% \mathrm{CI}$ \\
\hline $\begin{array}{l}\text { Age (for } 10 \text { years } \\
\text { increment) }\end{array}$ & 0.91 & $0.75-1.11$ & $0.89^{\mathrm{a}}$ & $0.69-1.15$ \\
\hline \multicolumn{5}{|l|}{ Comorbidity } \\
\hline No & 1 & & 1.00 & - \\
\hline $\mathrm{h} / \mathrm{w}$ pain & 2.06 & $0.83-5.14$ & $4.65^{\mathrm{a}}$ & $1.16-18.73$ \\
\hline $\mathrm{s} / \mathrm{n}$ pain & 0.67 & $0.41-1.10$ & $0.61^{\mathrm{a}}$ & $0.34-1.10$ \\
\hline $\mathrm{h} / \mathrm{w}$ and $\mathrm{s} / \mathrm{n}$ pain & 1.54 & $0.77-3.09$ & $2.56^{\mathrm{a}}$ & $0.95-6.89$ \\
\hline Herniated disc history & 0.61 & $0.36-1.04$ & $0.47^{\mathrm{a}}$ & $0.25-0.88$ \\
\hline Having kids & 0.81 & $0.56-1.18$ & 0.59 & $0.31-1.12$ \\
\hline $\begin{array}{l}\text { Low back pain in past } \\
12 \text { months }\end{array}$ & 0.81 & $0.56-1.18$ & 0.58 & $0.26-1.29$ \\
\hline
\end{tabular}

${ }^{\text {a }}$ Covariates of the final model

of $41 \%$ - was the most frequent single cause of absence among shipyard workers. Individual characteristics and prior absenteeism influenced the decision to take sick leave due to LBP. Prior sick leave due to LBP partly captured the effects of work-related factors. RTW was largely determined by a history of diagnosed herniated disc and musculoskeletal co-morbidity.

Our study considered various factors that may influence sickness absence due to LBP. A particular strength of this study was that the information about sickness absence was reliable, because the diagnosis was taken on return to work. Another strength was that all subjects worked in the same company and were comparable for several factors, such as cultural and socioeconomic factors. On the other hand, this may have hampered the influence of some work-related risk factors since there appears to be a limited contrast in some of the risk factors. The exposure information was self-reported, although objective measurements on individual characteristics like BMI took place. Since aspects of physical load were measured crudely on a four-point scale, these variables will lack discriminatory power [13, 19]. A substantial part of the study population with a MSD had gone on sick leave in the 12 months prior to the study. When work-related physical and psychosocial factors determine the risk on sick leave, it is expected that the inclusion on prior sick leave in the analysis will compromise the power of the current study to demonstrate the effect of work-related factors. In our study, when we excluded from the analysis all persons with previous sick leave due to LBP, work-related factors exhibited an influence of borderline significance. It seems that prior sick leave due to LBP partly captures the effect of work-related physical and psychosocial factors. Another disadvantage of this study is that psychological factors were not addressed and thus their potential influence on absenteeism could not be established. Another feature was that we did not examine support at work in the analysis. A previous study in the same population showed that $90 \%$ reported a highly supportive work environment and, thus, this has limited discriminatory power [8].

Of workers with LBP at baseline, the 1 year rate of absence due to LBP $(23.7 \%)$ in our study lies near of those reported in other cohort studies [7, 33]. However, these studies were based on self reports rather than sickness absence registries and some bias may have occurred.

In the proportional hazard analysis, several factors were evaluated for their influence on the probability of occurrence of sickness absence due to LBP. Prior absenteeism was the most important prognostic factor, which has also been shown in other studies [7, 29]. Previous sick leave due to LBP reflects actually recurrence while the influence of prior absenteeism due to other reasons most likely reflects coping behaviors. In total, $8.4 \%$ of those with no previous LBP took a sick leave due to LBP while recurrence was $23.7 \%$, higher than the rate reported in another study [35]. The few studies that have investigated risk factors for recurrence of sick leave due to LBP found various work related and psychological factors as predictors [24, 26, 32].

Low educational level was also an important predictor. It might reflect to a great extent (as surrogate) differences in work activities and working conditions between job titles. Those workers with the lowest education also reported a higher physical load and, hence, it was not possible to disentangle the separate effects of education and physical load. This may explain why physical load factors did not appear to have a significant influence on the occurrence of sick leave due to LBP. Furthermore, the impact of education might also reflect differences in coping strategies and work motivations [15].

Workers with night shift work had significantly less sickness absence due to LBP. The possible explanation for this finding is a self-selection process since those engaged in night shift were rather few, well paid, and not easily being replaced. This aspect of a healthy worker effect has been observed before among shift workers [22].

Living alone was found to predict future absenteeism, while another study showed contradictory results [7]. In our study population this may be due to the fact that workers on sick leave only received $50 \%$ compensation of their wage and, hence, may put their families under financial strain. Thus, living alone not only reflects marital status but also a different social and economic environment. Perhaps a more supportive environment at home may be a reason for earlier RTW.

Other individual characteristics such as age, height, weight, smoking, and duration of employment, were not predictive for low back complaints leading to absence from 
work. In contrast with other studies [9, 31, 32], workrelated factors did not exhibit a significant influence on absenteeism due to LBP in the whole study population, but when we excluded from the analysis subjects with a previous sick leave due to LBP, work-related physical, psychosocial factors, and need for recovery had an influence of borderline significance. It seems that prior sick leave due to LBP partly captured the effects of workrelated physical and psychosocial factors. Health-related aspects have been reported to be more strongly associated with sick leave than work-related aspects, which was reflected in our findings that prior absenteeism (health problems and coping behaviors) predicted the occurrence sickness absence.

On average, about $90 \%$ returned to work within 2 weeks. This is a higher RTW rate than reported in the literature $[12,28]$. A reason for this may be the low compensation $(50 \%)$. It is known that the sickness absence rate in Greece is among the lowest in Europe. While this is partly explained by the low social insurance benefits and the relatively high unemployment rate, other factors like the high percentage of permanent full-time employees and the high prevalences of reported morbidity (stress, MSDs, etc.) do not explain this large difference with other European populations [3].

In this study it was obvious that workers were not always fully recovered at return to work, given the high recurrence of sick leave due to LBP ( $43 \%$ in 1 year). It has been reported before that most workers experience residual low back complaints after returning to work [24]. This high return to work within the first weeks combined with the fact that in most cases employees suffered residual complaints when returned to work suggests that additional management after RTW may be of importance [24, 34].

Only a history of herniated disc and comorbidity with musculoskeletal complaints were significant prognostic factors for RTW. It is known that "specific" (lesions of vertebrae and discs) causes account for the most long-term absences compared to a "nonspecific" (pain, sprains, and strains) origin of complaints [20].

In the present study, having concurrent LBP and hand/ wrist pain was associated with a higher rate of return after a first spell of sickness absence. The opposite hold for concurrent shoulder/neck pain but this did not reach a statistically significant level. In another study having concurrent LBP and shoulder/neck pain was associated with a higher risk for sickness absence and also long-term sickness absence [27]. These findings suggest that in research on risk factors for sick leave and prognostic factors for RTW musculoskeletal comorbidity has to be taken into consideration.

Our study showed that individual and job characteristics (living alone, night shift, lower education, sick leave or care seeking during the last 12 months) influenced the decision to take sick leave due to LBP. An increased awareness of those frequently on sick leave and additional management after return to work may have a beneficial effect on the sickness absence pattern.

Open Access This article is distributed under the terms of the Creative Commons Attribution Noncommercial License which permits any noncommercial use, distribution, and reproduction in any medium, provided the original author(s) and source are credited.

\section{References}

1. Alexopoulos EC, Burdorf A (2001) Prognostic factors for respiratory sickness absence and return to work among blue collar workers and office personnel. Occup Environ Med 58(4):246252. doi:10.1136/oem.58.4.246

2. Alexopoulos EC, Tanagra D, Konstantinou E, Burdorf A (2006) Musculoskeletal disorders in shipyard industry: prevalence, health care use, and absenteeism. BMC Musculoskelet Disord 7:88. doi:10.1186/1471-2474-7-88

3. Bonato L, Lusinyan L (2004) Work absence in Europe. IMF Working Paper 04/193, Washington

4. Bonde JP, Rasmussen MS, Hjollund H, Svendsen SW, Kolstad HA, Jensen LD, Wieclaw J (2005) Occupational disorders and return to work: A randomized controlled study. J Rehabil Med 37:230-235. doi:10.1080/16501970410025487

5. Boot CR, Vercoulen JH, van der Gulden JW, van den Borne BH, Orbon KH, van Weel C, Folgering HT (2005) Sick leave in workers with asthma and COPD: the role of attitudes, perceived social norms and self efficacy. Patient Educ Couns 58:192-198. doi:10.1016/j.pec.2004.08.010

6. Borg G (1990) Psychophysical scaling with applications in physical work and the perception of exertion. Scand J Work Environ Health 16 Suppl. 1:55-58

7. Borg K, Hensing G, Alexanderson K (2004) Prediction of future low levels of sickness absence among young persons sick listed with back, neck, or shoulder diagnoses. Work 23:159-167

8. Charizani F, Moysiadou I, Siarkos E, Alexopoulos EC (2005) Subjective risk assessment of industry employees. Rev Clin Pharmacol Pharmacokinet 19:87-92

9. De Croon EM, Sluiter JK, Frings-Dresen MH (2003) Need for recovery after work predicts sickness absence: a 2-year prospective cohort study in truck drivers. J Psychosom Res 55:331339. doi:10.1016/S0022-3999(02)00630-X

10. Eriksen W, Bruusgaard D, Knardahl S (2004) Work factors as predictors of sickness absence attributed to airway infections; a three month prospective study of nurses' aides. Occup Environ Med 61:45-51. doi:10.1136/oem.2003.008482

11. Franche RL, Baril R, Shaw W, Nicholas M, Loisel P (2005) Workplace- based return-to-work interventions: optimizing the role of stakeholders in implementation and research. J Occup Rehabil 15:525-542. doi:10.1007/s10926-005-8032-1

12. Frank JW, Brooker AS, DeMaio SE, Kerr MS, Maetzel A, Shannon HS, Sullivan TJ, Norman RW, Wells RP (1996) Disability resulting from occupational low back pain.Part I: what do we know about secondary prevention? A review of the scientific evidence on prevention after disability begins. Spine 21:29182929. doi:10.1097/00007632-199612150-00025

13. Gheldof EL, Vinck J, Vlaeyen JW, Hidding A, Crombez G (2005) The differential role of pain, work characteristics and pain-related fear in explaining back pain and sick leave in occupational settings. Pain 113:71-81. doi:10.1016/j.pain.2004.09.040 
14. Guo HR, Tanaka S, Halperin WE, Cameron LL (1999) Back pain prevalence in US industry and estimates of lost workdays. Am J Public Health 89:1029-1035

15. Hagen KB, Tambs K, Bjerkedal T (2006) What mediates the inverse association between education and occupational disability from back pain?-A prospective cohort study from the NordTrondelag health study in Norway. Soc Sci Med 63(5):12671275. doi:10.1016/j.socscimed.2006.03.041

16. Head J, Kivimaki M, Martikainen P, Vahtera J, Ferrie JE, Marmot MG (2006) Influence of change in psychosocial work characteristics on sickness absence: The Whitehall II Study. J Epidemiol Community Health 60:55-61. doi:10.1136/jech.2005. 038752

17. Hiebert R, Skovron ML, Nordin M, Crane M (2003) Work restrictions and outcome of nonspecific low back pain. Spine 28:722-728. doi:10.1097/00007632-200304010-00019

18. Hlobil H, Staal JB, Spoelstra M, Ariens GA, Smid T, van Mechelen W (2005) Effectiveness of a return-to-work intervention for subacute low-back pain. Scand J Work Environ Health $31: 249-257$

19. Hoogendoorn WE, Bongers PM, de Vet HC, Ariens GA, van Mechelen W, Bouter LM (2002) High physical work load and low job satisfaction increase the risk of sickness absence due to low back pain: results of a prospective cohort study. Occup Environ Med 59:323-328. doi:10.1136/oem.59.5.323

20. Infante-Rivard C, Lortie M (1996) Prognostic factors for return to work after a first compensated episode of back pain. Occup Environ Med 53:488-494

21. Karasek R, Brisson C, Kawakami N, Houtman I, Bongers P, Amick B (1998) The job content questionnaire (JCQ): an instrument for internationally comparative assessments of psychosocial job characteristics. J Occup Health Psychol 3:322-355. doi:10.1037/1076-8998.3.4.322

22. Kleiven M, Boggild H, Jeppesen HJ (1998) Shift work and sick leave. Scand J Work Environ Health 24(Suppl. 3):128-133

23. Kuorinka I, Jonsson B, Kilbom A, Vinterberg H, BieringSorensen F, Andersson G, Jorgensen K (1987) Standardized Nordic questionnaires for the analysis of musculoskeletal symptoms. Appl Ergonom 18:233-237. doi:10.1016/0003-6870(87) 90010-X

24. Lotters F, Hogg-Johnson S, Burdorf A (2005) Health status, its perceptions, and effect on return to work and recurrent sick leave. Spine 30:1086-1092. doi:10.1097/01.brs.0000161484.89398.48
25. Luijsterburg PAJ, Bongers PM, de Vroome EMM (2005) A new bricklayers' method for use in the construction industry. Scand J Work Environ Health 31:394-400

26. Mercado AC, Carroll LJ, Cassidy JD, Cote P (2005) Passive coping is a risk factor for disabling neck or low back pain. Pain 117:51-57. doi:10.1016/j.pain.2005.05.014

27. Nyman T, Grooten WJ, Wiktorin C, Liwing J, Norrman L (2007) Sickness absence and concurrent low back and neck-shoulder pain: results from the MUSIC-Norrtalje study. Eur Spine J 16(5):631-638. doi:10.1007/s00586-006-0152-6

28. Pengel LH, Herbert RD, Maher CG, Refshauge KM (2003) Acute low back pain: systematic review of its prognosis. BMJ 327:323325. doi:10.1136/bmj.327.7410.323

29. Seferlis T, Nemeth G, Carlsson AM (2000) Prediction of functional disability, recurrences, and chronicity after 1 year in 180 patients who required sick leave for acute low-back pain. J Spinal Disord 13:470-477. doi:10.1097/00002517-200012000-00002

30. Steenstra IA, Verbeek JH, Heymans MW, Bongers PM (2005) Prognostic factors for duration of sick leave in patients sick listed with acute low back pain: a systematic review of the literature. Occup Environ Med 62:851-860. doi:10.1136/oem.2004.015842

31. Tubach F, Leclerc A, Landre MF, Pietri-Taleb F (2002) Risk factors for sick leave due to low back pain: a prospective study. J Occup Environ Med 44:451-458. doi:10.1097/00043764200205000-00013

32. van den Heuvel SG, Ariens GA, Boshuizen HC, Hoogendoorn WE, Bongers PM (2004) Prognostic factors related to recurrent low-back pain and sickness absence. Scand J Work Environ Health 30:459-467

33. Vingard E, Mortimer M, Wiktorin C, Pernold RPTG, Fredriksson K, Nemeth G, Alfredsson L (2002) Musculoskeletal Intervention Center-Norrtalje Study Group. Seeking care for low back pain in the general population: a two-year follow-up study: results from the MUSIC-Norrtalje Study. Spine 27:2159-2165. doi:10.1097/ 00007632-200210010-00016

34. Wahlgren DR, Atkinson JH, Epping-Jordan JE, Williams RA, Prutt SD, Klapow JC, Patterson TL, Grant I, Webster JS, Slater MA (1997) One-year follow-up of first onset low back pain. Pain 73:213-221. doi:10.1016/S0304-3959(97)00106-1

35. Wasiak R, Kim J, Pransky G (2006) Work disability and costs caused by recurrence of low back pain: longer and more costly than in first episodes. Spine 31:219-225. doi:10.1097/01.brs. 0000194774.85971.df 